\title{
Diastereomerically Pure Heterodi- and Heterotetrametallic (Pd and Pt) Compounds: A Study of the Effect Induced by the Binding Mode of a Ferrocene-Containing Ligand on Their Electrochemical Properties
}

\author{
Daniel Talancón ${ }^{[\mathrm{a}]}$ Concepción López ${ }^{*[\mathrm{a}]}$ Mercè Font-Bardía ${ }^{[\mathrm{b}]}$ Teresa Calvet ${ }^{,[\mathrm{c}]}$ and Olivier \\ Roubeau $^{[\mathrm{d}]}$
}

[a] Department de Química Inorgànica, Facultat de Química, Universitat de Barcelona, Martí i Franquès 1-11, 08028 Barcelona, Spain

E-mail: conchi.lopez@,qi.ub.es

http://www.ub.edu/inorgani/ca/recerca_qbo.html

[b] Unitat de Difracció de Raigs-X, Centre Científic i Tecnològic de la Universitat de Barcelona, Solé i Sabaris 1-3, 08028 Barcelona, Spain

[c] Departament de Cristallografia, Mineralogia i Dipòsits Minerals, Facultat de Geologia, Universitat de Barcelona, Martí i Franquès s/n, 08028 Barcelona, Spain

[d] Instituto de Ciencia de Materiales de Aragón, (ICMA) CSIC, Universidad de Zaragoza, Plaza San Francisco, s/n, 50009 Zaragoza, Spain

Keywords: Electrochemistry / Chirality / Coordination modes / Sandwich complexes / Cyclometallated compounds 
48 The reaction of $(1 \mathrm{~S}, 2 \mathrm{R})-[(\eta 5-\mathrm{C} 5 \mathrm{H} 5) \mathrm{Fe}\{(\eta 5-\mathrm{C} 5 \mathrm{H} 4)-\mathrm{CH}=\mathrm{NCH}(\mathrm{Me})-\mathrm{CH}(\mathrm{OH})(\mathrm{C} 6 \mathrm{H} 5)\}]$ (1) with

$49 \mathrm{Na} 2[\mathrm{PdCl} 4]$ in the presence of $\mathrm{Na}(\mathrm{OAc}) \cdot 3 \mathrm{H} 2 \mathrm{O}$ produced three diastereomerically pure tetrametallic

50 cyclopalladated complexes (6bI-6bIII). In two of them (6bI and 6bII), the imine 1 adopts the

51 [C(sp2,ferrocene), N]- mode of binding, but they differ in the planar chirality of the 1,2-ferrocenyl unit

52 (Sp in 6bI and $\mathrm{Rp}$ in 6bII), whereas ligand 1 in $6 \mathrm{bIII}$ acts as a [C(sp2,phenyl),N]- group. Treatment of

53 6bI-6bIII with $\mathrm{PPh} 3$ gave $[\mathrm{Pd}\{\kappa 2-\mathrm{C}, \mathrm{N}\{(\eta 5-\mathrm{C} 5 \mathrm{H} 3)-\mathrm{CH}=\mathrm{N}-\mathrm{CH}(\mathrm{Me})-\mathrm{CH}(\mathrm{OH})(\mathrm{C} 6 \mathrm{H} 5)\} \mathrm{Fe}(\eta 5-$

$54 \mathrm{C} 5 \mathrm{H} 5)\} \mathrm{Cl}(\mathrm{PPh} 3)](7 \mathrm{bI}, 7 \mathrm{bII})$ and $[\mathrm{Pd}\{\kappa 2-\mathrm{C}, \mathrm{N}\{(\mathrm{C} 6 \mathrm{H} 4)-\mathrm{CH}(\mathrm{OH})-\mathrm{CH}(\mathrm{Me})-\mathrm{N}=\mathrm{CH}-(\eta 5-\mathrm{C} 5 \mathrm{H} 4)\} \mathrm{Fe}(\eta 5-$

$55 \mathrm{C} 5 \mathrm{H} 5)\} \mathrm{Cl}(\mathrm{PPh} 3)](7 \mathrm{bIII})$. The PtII compounds $[\mathrm{Pt}\{\kappa 2-\mathrm{C}, \mathrm{N}\{(\eta 5-\mathrm{C} 5 \mathrm{H} 3)-$

$56 \mathrm{CH}=\mathrm{NCH}(\mathrm{Me}) \mathrm{CH}(\mathrm{OH})(\mathrm{C} 6 \mathrm{H} 5)\} \mathrm{Fe}(\eta 5-\mathrm{C} 5 \mathrm{H} 5)\} \mathrm{Cl}(\mathrm{PPh} 3)][(\mathrm{Sp}, 1 \mathrm{~S}, 2 \mathrm{R})$ and $(\mathrm{Rp}, 1 \mathrm{~S}, 2 \mathrm{R})$ diastereomers,

57 7Ai and 7aII, respectively)] have also been prepared. The results of electrochemical studies of 6bI-6bIII,

58 7bI-7bIII, 7aI, 7aII and related PtII complexes with 1 acting as an $(\mathrm{N})$ or $(\mathrm{N}, \mathrm{O})$ - ligand are also

59 reported. Comparison of the results provides conclusive evidence for the relative influence of the mode

60 of binding of the ligand, the nature of the MII atom, the type of metallated atom C(sp2,phenyl or

61 ferrocenyl), the ancillary ligands and their relative disposition on the electrochemical properties of this

62 type of compound.

63

64

65

66

67 
70 One of the most exciting areas of modern organometallic chemistry is centred on the synthesis of novel

71

72 ferrocene derivatives, the study of their properties and their potential applications in a wide variety of areas that include synthesis, catalysis, biology, advanced materials and biomedicine.[1-3] The existence of a redox centre in these products makes them also especially useful for the design of electrochemical devices such as molecular machines, switches and sensors..[4] In addition, the rich and versatile chemistry of ferrocene permits the incorporation of substituents and functional groups into one or both rings and at different sites.[1,2] The presence of heteroatoms (i.e., N, P, O or S) and/or unsaturated groups with good donor abilities is particularly important due to their ability to act as ligands for other metal ions to achieve heterodi-, heterotri- or, in general, heteropolymetallic complexes. In these systems, the presence of proximal metals in different environments with different oxidation numbers and spin states may influence their mutual cooperation in a variety of processes and, in particular, may allow not only the modification of the electrochemical properties of the ferrocenyl unit, but also the introduction or promotion of other properties or activities by external stimulus (e.g., light, $\mathrm{pH}$ ) or vice versa.[1,5,6]

On the other hand, it is well known that 1) ferrocene derivatives with additional $-\mathrm{C}(\mathrm{R})=\mathrm{N}-$ or heterocyclic rings are valuable ligands for PdII and PtII [5,6] and 2) ring-chain tautomeric equilibria between imines and 1,3-(N,O) heterocycles (i.e., oxazolines or oxazines, Scheme 1) affect the reactivity of the two species involved in this process. [7,8] This property is important not only because of their utility in organic and organometallic synthesis, but also in physical and medicinal chemistry.[7,8] Unfortunately, examples of ferrocenyl imines showing this type of behaviour are extremely scarce[9,10] and studies on their reactivity with transition-metal salts are even less common. One of the latest examples of ring-chain tautomerism of ferrocene derivatives is that of the imine (1S,2R)-[( $\eta 5$ $\mathrm{C} 5 \mathrm{H} 5) \mathrm{Fe}\{(\eta 5-\mathrm{C} 5 \mathrm{H} 4)-\mathrm{CH}=\mathrm{NCH}(\mathrm{Me})-\mathrm{CH}(\mathrm{OH}) \mathrm{C} 6 \mathrm{H} 5\}](1)[10]$ and its closed form 2 (Scheme 2, step i).

Recent studies have shown that imine 1 can adopt a variety of binding modes, $[(\mathrm{N}),(\mathrm{N}, \mathrm{O})]-$ or [C(sp2,ferrocene), $\mathrm{N}]-,[11]$ and hapticities in PtII complexes. In fact, an accurate control of the experimental conditions used in the reaction of 1 with cis-[PtCl2( $\mathrm{dmso}) 2][11]$ produced the preferential formation of each of the six diastereomerically pure platinum(II) complexes 3aI, 3aII, 4aI, 4aII, 5aI and 5aII (Figure 1), some of them exhibiting greater anti-proliferative activity than cisplatin against lung (A549), breast (MDA-MB-231) and colon (HCT-116) cancer cell lines.[11]

This outstanding versatility in the coordination of 1 with PtII, the relevance of enantio- and diastereomerically pure PdII complexes in homogeneous catalysis and in asymmetric synthesis,[12] and the increasing interest in the electrochemical properties of transition-metal complexes with ferrocenyl ligands $[1,2,6 \mathrm{a}, 6 \mathrm{e}, 13]$ prompted us to explore the reactivity of compound 1 with PdII salts or complexes and to compare 1) the effects induced by the binding mode of 1 in the palladium(II) complexes on the proclivity of the ferrocenyl ligand to oxidation and 2) their electrochemical behaviour with those of the PtII derivatives depicted in Figure 1. Herein we present three types of diastereomerically pure heterotetra- $(\mathrm{Pd} 2 \mathrm{Fe} 2)$ or heterodimetallic $[(\mathrm{Pd}, \mathrm{Fe})$ or $(\mathrm{Pt}, \mathrm{Fe})]$ complexes and a comparative study of their electrochemical properties. 


\section{Heterotetrametallic Compounds}

Treatment of (1S,2R)-[( $75-\mathrm{C} 5 \mathrm{H} 5) \mathrm{Fe}\{(\eta 5-\mathrm{C} 5 \mathrm{H} 4)-\mathrm{CH}=\mathrm{NCH}(\mathrm{Me})-\mathrm{CH}(\mathrm{OH})(\mathrm{C} 6 \mathrm{H} 5)\}]$ (1) with equimolar amounts of $\mathrm{Na} 2[\mathrm{PdCl} 4]$ and $\mathrm{Na}(\mathrm{OAc}) \cdot 3 \mathrm{H} 2 \mathrm{O}$ in methanol at $298 \mathrm{~K}$ for $40 \mathrm{~h}$ followed by $\mathrm{SiO} 2$ column chromatography gave small amounts of ferrocenecarbaldehyde and three different di- $\mu$-chlorido-bridged cyclopalladated complexes 6bI, 6bII and 6bIII (Scheme 2, step ii) in a relative abundance $6 \mathrm{bI} / 6 \mathrm{bII} / 6 \mathrm{bIII}$ of 1.0:0.9:0.4. The major components (6bI and 6bII) were isolated as garnet solids after elution with first $\mathrm{CHCl} 3$ (for 6bI) and then with a $\mathrm{CHCl} 3 / \mathrm{MeOH}(100: 0.2)$ mixture (for 6bII). Note that the relative abundance of the three isomers did not change substantially when the reaction period was increased from 24 to 72 h.[14]

The characterization data for compounds 6bI-6bIII (see the Supporting Information) indicate that they are formed by metallation of the ( $\eta 5-\mathrm{C} 5 \mathrm{H} 4)$ ring (for $6 \mathrm{bI}$ and $6 \mathrm{bII})$ and the phenyl ring (6bIII). In these isomers the two halves of the molecules could be in either a cis or trans disposition. Moreover, because the formation of the $\sigma[\mathrm{Pd}-\mathrm{C}(\mathrm{sp} 2$,ferrocene)] bond induces planar chirality,[1-3,13a] for $6 \mathrm{bI}$ and $6 \mathrm{bII}$ the two metallated units could have identical ( $\mathrm{Sp}$ and $\mathrm{Sp}$ or Rp and Rp) or different (Sp and $\mathrm{Rp}$ ) planar chirality. The results obtained from the reactions of 6bI and 6bII with PPh3 (see below) revealed that the absolute configuration of the ferrocenyl unit was $(\mathrm{Sp}, \mathrm{Sp})$ in $6 \mathrm{bI}$ and $(\mathrm{Rp}, \mathrm{Rp})$ in 6bII,

The minor product, 6bIII [isolated after the elution with $\mathrm{CHCl} / \mathrm{MeOH}(100: 0.4)$ and concentration] arose from the activation of the $\sigma[\mathrm{C}(\mathrm{sp} 2$,phenyl) $-\mathrm{H}]$ bond. Its X-ray crystal structure[15] (Figure 2) confirmed 1) the existence of a central and planar "Pd( $\mu-\mathrm{Cl}) 2 \mathrm{Pd}$ " unit, 2) a cis disposition of the two halves of the molecule, 3 ) the syn (Z) form adopted by the imine in the complex and 4) the $[\mathrm{C}(\mathrm{sp} 2$, phenyl),N]-mode of binding of the ligand.

In the crystal structure, the separation between the $\mathrm{Cl1S}$ (or $\mathrm{Cl} 2 \mathrm{~S}$ ) atoms of the $\mathrm{CH} 2 \mathrm{Cl} 2$ molecules and the hydrogen atoms $\mathrm{H} 9 \mathrm{~B}$ (and $\mathrm{H} 13 \mathrm{~B}$, respectively) is smaller than the van der Waals radii of these atoms[16] and suggests $\mathrm{C}-\mathrm{H} \cdots \mathrm{Cl}$ interactions that lead to supramolecular chains, as shown in Figure 3 .

The results obtained in the reaction shown in Scheme 2 (step i) and, in particular, the formation of 6bIII, are markedly different from those reported for [( $55-\mathrm{C} 5 \mathrm{H} 5) \mathrm{Fe}\{(\eta 5-\mathrm{C} 5 \mathrm{H} 4)-\mathrm{CH}=\mathrm{N}-(\mathrm{CH} 2) \mathrm{n}-(\mathrm{C} 6 \mathrm{H} 5)\}](\mathrm{n}=$ $0,1$ or 2$)$, which, under identical experimental conditions, underwent cyclopalladation of the ferrocenyl unit exclusively, even for $n=2$.[17] These findings suggest that the presence of the $-\mathrm{Me}$ and $-\mathrm{OH}$ substituents on the vicinal carbons of the - $(\mathrm{CH} 2) 2$-chain is important for modifying the regioselectivity of the cyclopalladation process.

Finally, note that despite the fact that 1) ligand 1 coexists with the closed form 2 in solution[10] and 2) several examples of PdII complexes formed by the coordination of oxazines (involved in ring-chain tautomeric processes) have been reported,[18] in our case no evidence of the presence of PdII complexes containing any of the diastereomers of the closed form (2) as ligand has been provided by $1 \mathrm{H}$ NMR studies of the crude of the reaction. This suggests that the open form 1 is more prone to bind to the PdII centre than the heterocyclic form, in good agreement with the results obtained in the reaction of 1 with cis-[PtCl2(dmso)2].[11]

\section{Heterodimetallic Compounds}

The addition of $\mathrm{PPh} 3$ to $\mathrm{CH} 2 \mathrm{Cl} 2$ solutions of the corresponding di- $\mu$-chlorido-bridged products $6 \mathrm{bI}, 6 \mathrm{bII}$ or $6 \mathrm{bIII}$ in a molar ratio $2: 1$ produced the splitting of the central " $\mathrm{Pd}(\mu-\mathrm{Cl}) 2 \mathrm{Pd}$ " units and the formation of the monomeric derivatives 7bI, 7bII and 7bIII, respectively (Scheme 2, step iii). The characterization 
data (see the Supporting Information) agreed with the proposed formulae. Note that the signal observed in the $31 \mathrm{P}\{1 \mathrm{H}\}$ NMR spectrum of $7 \mathrm{bIII}(\delta=32.4 \mathrm{ppm})$ appears at a higher field than in the spectra of $7 \mathrm{bI}$ and $7 \mathrm{bII}(\delta=37.4$ and $37.8 \mathrm{ppm}$, respectively). This may be due to the different influence of the metallated carbon [C(sp2,phenyl) in 7bIII vs. C(sp2,ferrocene) in 7bI and 7bII). NMR studies of the three products confirmed the cis arrangement of the phosphido ligand and the metallated carbon, in good agreement with the transphobia effect.[19]

The X-ray crystal structure of $7 \mathrm{bII}$ [20] confirmed the formation of the heterodimetallic molecules $[\mathrm{Pd}\{\kappa 2-\mathrm{C}, \mathrm{N}\{(\eta 5-\mathrm{C} 5 \mathrm{H} 3)-\mathrm{CH}=\mathrm{N}-\mathrm{CH}(\mathrm{Me})-\mathrm{CH}(\mathrm{OH})(\mathrm{C} 6 \mathrm{H} 5)\} \mathrm{Fe}(\eta 5-\mathrm{C} 5 \mathrm{H} 5)\} \mathrm{Cl}-(\mathrm{PPh} 3)]$ (Figure 4).

In each molecule, the PdII is in a square-planar environment in which it is bound simultaneously to the imine nitrogen $\{\mathrm{N}(1)\}$ and the ortho carbon $\{\mathrm{C}(6)\}$ of the substituted ring of the ferrocenyl unit. This confirms the [C(sp2,ferrocene), N]- binding mode of ligand 1 in 7bII. A chlorido and the phosphorus of the $\mathrm{PPh} 3$ ligand complete the coordination sphere. The angle of $\mathrm{C}(6)-\mathrm{Pd}(1)-\mathrm{P}\left[95.3(2)^{\circ}\right]$ indicates a cis arrangement to the metallated carbon, in good agreement with the results obtained from NMR studies and the transphobia effect.[10]

To compare the effect induced by the PdII or PtII metals on the electrochemical behaviour of the (Sp,1S,2R) and (Rp,1S,2R) diastereomers of [ $\mathrm{M}\{\kappa 2-\mathrm{C}, \mathrm{N}\{(\eta 5-\mathrm{C} 5 \mathrm{H} 3)-\mathrm{CH}=\mathrm{NCH}(\mathrm{Me})-\mathrm{CH}(\mathrm{OH})$ $(\mathrm{C} 6 \mathrm{H} 5)\} \mathrm{Fe}(\eta 5-\mathrm{C} 5 \mathrm{H} 5)\} \mathrm{Cl}(\mathrm{PPh} 3)]$, we also prepared the PtII complexes. Treatment of the platinacycles $[\mathrm{Pt}\{\kappa 2-\mathrm{C}, \mathrm{N}\{(\eta 5-\mathrm{C} 5 \mathrm{H} 3)-\mathrm{CH}=\mathrm{N}-\mathrm{CH}(\mathrm{Me})-\mathrm{CH}(\mathrm{OH})(\mathrm{C} 6 \mathrm{H} 5)\}-\mathrm{Fe}(\eta 5-\mathrm{C} 5 \mathrm{H} 5)\} \mathrm{Cl}(\mathrm{dmso})]$ (5aI or 5aII, Scheme 3) with an equimolar amount of $\mathrm{PPh} 3$ in $\mathrm{CH} 2 \mathrm{Cl} 2$ at $298 \mathrm{~K}$ gave, after work-up, the desired complexes $7 \mathrm{aI}$ and $7 \mathrm{aII}$, respectively. The positions of the signals detected in the $31 \mathrm{P}\{1 \mathrm{H}\}$ and $195 \mathrm{Pt}\{1 \mathrm{H}\}$ NMR spectra, as well the 1JPt,P coupling constant, are in good agreement with those reported for related platinacycles such as the $(\mathrm{Sp}, \mathrm{SC})$ and $(\mathrm{Rp}, \mathrm{SC})$ diastereomers of $[\mathrm{Pt}\{\kappa 2-\mathrm{C}, \mathrm{N}\{(\eta 5-$ $\mathrm{C} 5 \mathrm{H} 3)-\mathrm{CH}=\mathrm{N}-\mathrm{CH}(\mathrm{R})-\mathrm{CH} 2(\mathrm{OH})\} \mathrm{Fe}(\eta 5-\mathrm{C} 5 \mathrm{H} 5)\} \mathrm{Cl}(\mathrm{PPh} 3)](\mathrm{R}=\mathrm{Me}$ or $\mathrm{PP})$ in which the $\mathrm{PPh} 3$ ligand and the metallated carbon atom are in a cis disposition.[13a,13b]

\section{Electrochemical Studies}

In a first attempt to elucidate the effects produced by the mode of binding of the Schiff base to the MII ions, the nature of the ancillary ligands bound to them and their relative arrangement in the electronic environment of the iron(II), we decided to explore the electrochemical properties of the PtII and PdII compounds 3aI, 3aII, 4aI, 4aII, 5aI, 5aII, 7aI, 7aII, 5bI-5bIII and 7bI-7bIII shown in Figure 1 and Schemes 2 and 3. Note that the $1 \mathrm{H}$ NMR spectra of all the products in $\mathrm{CD} 3 \mathrm{CN}$ revealed they are stable in this solvent. The electrochemical studies were carried out by cyclic voltammetry of freshly prepared solutions $(10-3 \mathrm{~m})$ in acetonitrile with $(\mathrm{Bu} 4 \mathrm{~N})[\mathrm{PF} 6]$ as the supporting electrolyte. All these experiments were carried out at different scan rates $\mathrm{v}(\mathrm{v}=0.05-1.0 \mathrm{Vs}-1)$. The electrochemical data for all the compounds under study are presented in Table 1 and the cyclic voltammograms (hereinafter referred to as CVs) obtained at $298 \mathrm{~K}$ and a scan rate of $\mathrm{v}=0.1 \mathrm{Vs}-1$ for the PtII and PdII complexes are depicted in Figures 5-7.

First, we will describe the results obtained for the monomeric PtII complexes. As shown in Figure 5 and Figure 6 , the CVs exhibit one anodic peak with a directly associated reduction in the reverse scan. The Ipa/Ipc ratios are close to 1 and the relationship between Ipa and $\mathrm{v}^{1 / 2}$ is lineal. According to the literature, all these findings are consistent with those expected for a simple reversible one-electron process.[21] The main differences between the CVs arise from the positions of the waves that shift

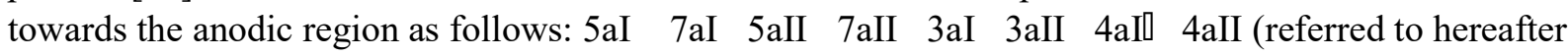
as sequence $\mathrm{A}$ ).

It is well known that the proclivity of ferrocene derivatives to oxidation is strongly dependent on the nature of the substituents. $[1,10,13]$ In general, the presence of electronwithdrawing groups is reflected 
by an increase in the Epa value, whereas donor groups produce the opposite effect. On this basis, several

199 conclusions can be reached from sequence A. First, the electrochemical properties of these PtII

200 complexes depend on several factors. One of them is the binding mode of the ligand. Compounds with 1

201 acting as a [C(sp2,ferrocene),N]- ligand (5aI, 5aII, 7aI and 7aII) are more prone to oxidation than 3aI

202 and 3 aII in which the imine binds through the nitrogen atom exclusively, whereas complexes in which 1

203 acts as a (N,O)- ligand (4aI and 4aII) are less likely to undergo oxidation.

204 Secondly, the differences detected in the CVs of the pair of compounds 3aI and 3aII suggest that the trans-"PdCl2(dmso)" moiety bound to the imine nitrogen has a greater electron-withdrawing effect than if the two $\mathrm{Cl}$ - ligands are in a cis disposition. For the isomers $4 \mathrm{aI}$ and 4aII, the effect produced by the relative arrangement of the dmso and $\mathrm{Cl}$ - ligands (at a five-bond distance from the ferrocenyl unit) is not as strong as in $3 \mathrm{aI}$ and 3aII, in which the monodentate groups are closer to the organometallic array.

For the cycloplatinated complexes 5aI, 5aII, 7aI and 7aII, replacement of the dmso ligand of 5aI or 5aII by $\mathrm{PPh} 3$ to yield $7 \mathrm{aI}$ and 7aII, respectively, produced displacement of the wave to the anodic region. The magnitude of this shift is greater than those observed for the other two pairs of isomeric PtII complexes (i.e., 3aI and 3aII, 4aI and 4aII).

Furthermore, for compounds 7aI, 7aII, 7bI and 7bII, which differ in the planar chirality of the 1,2ferrocenyl unit, the differences are greater than those reported for related palladacycles, such as those derived from (Sp,1SC)-and (Rp,1SC)-[Pt $\{\kappa 2-\mathrm{C}, \mathrm{N}\{(\eta 5-\mathrm{C} 5 \mathrm{H} 3)-\mathrm{CH}=\mathrm{N}-\mathrm{CH}(\mathrm{R})-\mathrm{CH} 2-(\mathrm{OH})\} \mathrm{Fe}(\eta 5-$ $\mathrm{C} 5 \mathrm{H} 5)\} \mathrm{Cl}(\mathrm{PPh} 3)](\mathrm{R}=\mathrm{Me}$ or $\mathrm{PPr})$.[13b] In addition, comparison of the electrochemical properties of compounds $7 \mathrm{aI}$ and $7 \mathrm{bI}$ indicate that the PdII complex is less prone to oxidation than it PtII analogue. The same trend is found for the couple $7 \mathrm{aII}$ and $7 \mathrm{bII}$.

The CVs of the dimeric and tetrametallic complexes 6bI- 6bIII (Figure 7) show one anodic peak with a directly associated reduction peak in the reverse scan, which suggests that there is no electronic communication between the two ferrocenyl units. Note that for 6bIII the wave is strongly shifted to the anodic region when compared with those of $6 \mathrm{bI}$ and 6bII. Thus, on this basis, comparison of the positions of the anodic peak for compounds $6 \mathrm{bI}, 6 \mathrm{bII}$ and $6 \mathrm{bIII}$, or their partners $7 \mathrm{bI}, 7 \mathrm{bII}$ and $7 \mathrm{bIII}$ (Figure 7), indicate that the metalation of the phenyl ring produces an electron-withdrawing effect on the ferrocenyl unit.

For the couples 7aI, 7bI and 7aII, 7bII, which differ in the nature of the MII ion, the replacement of the PtII in 7aI or 7aII by PdII (to yield 7bI or 7bII, respectively) produces a shift of the wave to the anodic region. This means that the palladium(II) complexes are less prone to oxidation than their PtII analogues. 
233 The results presented herein have allowed us to prepare two series of three sets of diastereomerically 234 pure cyclopalladated complexes containing four (in 6bI-6bIII) or two (in 7bI-7bIII) metal centres. In each series, the complexes differ in the nature of the metallated carbon [C(sp2),ferrocene in 6bI, 6bII, $7 \mathrm{bI}$ and $7 \mathrm{bII}$, or $\mathrm{C}(\mathrm{sp} 2)$, phenyl in $6 \mathrm{bIII}$ and $7 \mathrm{bIII}]$ or in the planar chirality of the ferrocenyl unit (Rp in $6 \mathrm{bI}$ and $7 \mathrm{bI}$, and $\mathrm{Sp}$ in $6 \mathrm{bI}$ and $7 \mathrm{bI}$ ). Although the regio- and diastereoselectivity of the process is low, it provides a simple method for achieving diastereomerically pure organometallic palladium(II) with two stereogenic carbon centres with (in 6bI, 6bII, 7bI and 7bII) or without (in 6 $6 \mathrm{bII}$ and 7bIII) planar chirality. The new PdII complexes presented herein appear to be excellent candidates for use not only as precursors in asymmetric synthesis or catalysis, but also as electrochemical reagents.

Among the organic compounds that exhibit a similar rich and versatile chemistry in the presence of PdII and PtII atoms, ligand 1 is, to the best of our knowledge, the first that can 1) generate a variety of diastereomerically pure complexes with ferrocenyl units, 2) adopt up to four different binding modes $[(\mathrm{N}),(\mathrm{N}, \mathrm{O})]-,[\mathrm{C}(\mathrm{sp} 2$, ferrocene $), \mathrm{N}]$ or $[\mathrm{C}(\mathrm{sp} 2$, phenyl),N]- and 3) produce different types of isomeric forms of the PdII or PtII complexes.

In addition, a comparative study of the electrochemical behaviour of the new PdII and PtII complexe 248 prepared in this work (6bI-6bIII, 7bI-7bIII, 7aI and 7aII) and those closely related (3aI, 3aII, 4aI, 4aII,

$2495 \mathrm{aI}$ and 5aII) provide conclusive evidence of the relative important influence of 1) the binding mode of 250 the ligand to the metal centre $\{[\mathrm{C}(\mathrm{sp} 2$,ferrocene $), \mathrm{N}]-$ in 5aI, 5aII, 6bI, 6bII, 7aI, 7aII, 6bI and 6bII, 251 [C(sp2,phenyl),N]- in 6bIII and 7bIII, (N) in 3aI and 3aII or (N,O)- in 4aI and 4aII $\}, 2)$ the type of metal ion (PdII or PtII), 3) the nature of the remaining ligands bound to the metal and 4) their relative disposition on the electrochemical properties of the product. An accurate selection of the product allows the fine-tuning of the anodic and cathodic potentials in a wide range (i.e., the maximum difference in the Epa values is ca. $0.45 \mathrm{~V}$ ). Thus, these products are also attractive in view of their potential utility as selective and specific electrochemical sensors or detectors.

Moreover, the presence of an -OH group in the pendant arm of most of these PdII and PtII complexes (3aI, 3aII, 5aI, 5aII, 6bI, 6bII, 7aI, 7aII, 7bI and 7bII) opens up new possibilities and applications in other interesting fields. These products are similar to the PtII complexes derived from [( $\eta 5-\mathrm{C} 5 \mathrm{H} 5) \mathrm{Fe}(\eta 5-$ $\mathrm{C} 5 \mathrm{H} 4)-\mathrm{CH}=\mathrm{N}-(\mathrm{C} 6 \mathrm{H} 4-2-\mathrm{OH})]$, which exhibit behaviour typical of acid/base-dependent molecular switches.[13b] The compounds presented herein are optically pure and consequently they appear to be extremely useful for the development of $\mathrm{pH}$-dependent chiral molecular switches. Further work in this area is under way. 


\section{Preparation of the Compounds}

Compounds 6bI and 6bII: $\mathrm{Na} 2[\mathrm{PdCl} 4]$ (237 mg, 8.06ロ 10-4 mol) and $\mathrm{NaOAc} \cdot 3 \mathrm{H} 2 \mathrm{O}(110 \mathrm{mg}$, The reaction mixture was stirred at $298 \mathrm{~K}$ for $40 \mathrm{~h}$. After this period, the solution was concentrated to dryness on a rotary evaporator and the deep-red residue was dissolved in the minimum amount of $\mathrm{CHCl} 3$ and passed through a column of $\mathrm{SiO} 2(25 \square 50 \mathrm{~mm})$. Elution with $\mathrm{CHCl} 3$ produced two bands. The first eluted was pale orange and gave, after concentration, small amounts of ferrocenecarbaldehyde. The second was red-garnet and produced, after concentration, compound $6 \mathrm{bI}(122 \mathrm{mg})$. Further elution with $\mathrm{CHCl} 3 / \mathrm{MeOH}(100: 0.01)$ gave a mixture of the two diastereomers 6bI and 6bII (32 $\mathrm{mg})$ in a 1:1 molar ratio. The subsequent use of $\mathrm{CHCl} / \mathrm{MeOH}$ (100:0.02) as eluent produced compound 6bII (109 $\mathrm{mg})$.

Compound 6bIII: This compound was isolated as a minor component during the preparation of the palladacycles $6 \mathrm{bI}$ and $6 \mathrm{baII}$. Once the band containing isomer $6 \mathrm{bII}$ had been collected, the eluent was replaced by $\mathrm{CHCl} 3 / \mathrm{MeOH}$ (100:0.4). This produced an orange solution that gave, after evaporation of the solvent, isomer 6bIII (54 mg).

Compound 7bI: PPh3 (21 mg, 8.19] 10-5 mol) was added to a solution of compound 6bI (40 mg, 4.10 10-5 mol) in $\mathrm{CH} 2 \mathrm{Cl} 2$ and the mixture was stirred at $298 \mathrm{~K}$ for $30 \mathrm{~min}$. After this period, the mixture was concentrated to around $5 \mathrm{~mL}$ and passed through a short column of $\mathrm{SiO} 2(15 \square 20 \mathrm{~mm})$ using $\mathrm{CH} 2 \mathrm{Cl} 2$ as eluent and the deeporange band produced was collected and concentrated to dryness on a rotary evaporator to give complex $7 \mathrm{bI}$, which was then dried in vacuo for 5 days (yield: $54 \mathrm{mg}, 88$ $\%)$.

Compound 7bII: This product was prepared by using the same procedure as described above for 7bI but by using isomer 6bII (18 mg, 1.84】 10-5 mol) and PPh3 (10 mg, 3.69】 10-5 mol) as the starting materials (yield: $20 \mathrm{mg}, 71 \%$ ).

Compound 7bIII: PPh3 (8 mg, 3.07[ 10-5 mol) was added to a solution of 6bII (20 mg, 1.54[ 10-5 $\mathrm{mol})$ in $\mathrm{CH} 2 \mathrm{Cl} 2(10 \mathrm{~mL})$ and the mixture was stirred at $298 \mathrm{~K}$ for $30 \mathrm{~min}$. After this period, the mixture was filtered and the filtrate was concentrated to dryness on a rotary evaporator and the solid formed was then collected and dried in vacuo for 5 days (yield: $19 \mathrm{mg}, 83 \%$ ).

Compounds 7aI and 7aII: The corresponding isomer, 5aI or 5aII (40 mg, 6.11] 10-5 mol), was dissolved in $\mathrm{CH} 2 \mathrm{Cl} 2(10 \mathrm{~mL})$ and then an equimolar amount of PPh3 $(18 \mathrm{mg})$ was added. The reaction mixture was stirred at $298 \mathrm{~K}$ for $30 \mathrm{~min}$, concentrated in vacuo to around $5 \mathrm{~mL}$ and then the solution was passed through a short column of $\mathrm{SiO} 2(20 \square 30 \mathrm{~mm})$. Elution with $\mathrm{CH} 2 \mathrm{Cl} 2$ produced a red band that gave, after concentration, a deep-red solid that was collected and dried in vacuo for 5 days (yields: $44 \mathrm{mg}, 86 \%$ and $41 \mathrm{mg}, 80 \%$ for $7 \mathrm{bI}$ and $7 \mathrm{aII}$, respectively).

CCDC-940607) (for 6bIII) and -940608 (for 7bII) contain the supplementary crystallographic data for this paper. These data can be obtained free of charge from The Cambridge Crystallographic Data Centre via www.ccdc.cam.ac.uk/data_request/cif.

Supporting Information (see footnote on the first page of this article): Detailed characterization data (elemental analyses, mass spectra, IR, UV/Vis, optical rotations, Rf values and NMR) for the PdII compounds 6aI-6aIII and 7bI-7bIII, and the PtII complexes 7aI and 7aII. 
309

310 This work was supported by the Spanish Ministerio de Ciencia e Innovación (MICINN) [grant number 311 CTQ2009-11501 (subprogram BQU)]. O. R. is also thankful for the access to the ESRF CRG-BM16 312 beamline in Grenoble. 
[1] a) A. Togni, T. Hayashi (Eds.), Ferrocenes. Homogeneous Catalysis, Organic Synthesis Materials Science, VCH, Weinheim, Germany, 1995; b) P. Stepnicka (Ed.), Ferrocene. Ligands, Materials and Biomolecules, Wiley-VCH, Weinheim, Germany, 2008; c) L.-X. Dai, X-L. Hou (Eds.), Chiral Ferrocenes in Asymmetric Catalysis, Wiley-VCH, Weinheim, Germany, 2010.

For recent reviews, see, for example: a) F. L. Lam, F. Y. Kwong, A. S. C. Chan, Top. Organomet. Chem. 2011, 36, 29-66; b) E. Manoury, R. Poli, Catal. Met. Complexes 2011, 37, 121-149; c) U. Siemeling, Eur. J. Inorg. Chem. 2012, 3523-3536; d) D. J. Young, S. W. Chien, T. S. A. Hor, Dalton Trans. 2012, 41, 12655-12665; e) P. L. Diaconescu, Comments Inorg. Chem. 2010, 31, 196-241; f) R. Horikoshi, T. Mochida, Eur. J. Inorg. Chem. 2010, 5355-5371; g) N. Fletcher, M. C. Lagunas, Top. Organomet. Chem. 2010, 28, 143-170; h) O. N. Kadkin, Y. G. Galyametdinov, Russ. Chem. Rev. 2012, 81, 675-699; i) K. Heinze, M. Beckmann, K. Hemple, Chem. Eur. J. 2008, 14, 9468-9480; j) P. Molina, A. Tárrega, M. Alfonso, Eur. J. Org. Chem. 2011, 4505-4518.

[3] For a general overview of applications of ferrocene derivatives, see: a) I. S. Butler, R. P. Kengne-Momo, A. Vessieres, G. Jaouen, C. Policar, Appl. Spectrosc. Rev. 2012, 47, 620-632; b) U. Siemeling, Eur. J. Inorg. Chem. 2012, 3523-3536; c) F. L. Lam, F.-Y. Kwong, A. S. C. Chen, Top. Organomet. Chem. 2011, 36, 29-66; d) H. Pellissier, Adv. Synth. Catal. 2011, 353, 1613-1666; e) I. Bratsosm, T. Gianferrara, E. Alessio, C. G. Hartinger, M. A. Jakupec, B. K. Keppler, Bioinorg. Med. Chem. 2011, 151-176; f) L. V. Segur, V. N. Bavin, A. A. Simenel, Y. S. Nek rasov, L. A. Ostrovskaya, N. S. Sergeeva, Russ. Chem. Bull. 2010, 59, 2167-2178. a) C. M. Silveria, M. G. Almeida, Anal. Bioanal. Chem. 2013, 406, 3619-3635; b) K. Tsuchiya, H. Yajima, H. Sakai, M. Abe, Elect. Phen. Interfac. Biinterfaces 2012, 567-582; c) M. Senel, Adv. Chem. Res. 2012, 10, 393-408; d) B. Lai, A. Badshahm, A. A. Altaf, N. Khan, S. Ullah, Appl. Organomet. Chem. 2011, 25, 843-866; e) H. Tan, C.-C. E. Wang, Mol. Switches 2011, 1, $301-319$. 
[5] a) C. López, S. Pérez, X. Solans, M. Font-Bardía, T. Calvet, New J. Chem. 2010, 34, 676-685;

b) S. Pérez, C. López, A. Caubet, R. Bosque, X. Solans, M. Font-Bardía, Eur. J. Inorg. Chem. 2008, 1599-1612.

a) C. López, A. González, R. Bosque, P. K. Basu, M. Font-Bardía, T. Calvet, RSC Adv. 2012, 2, 1986-2002; b) A. Moyano, M. Rosol, R. M. Moreno, C. López, M. A. Maestro, Angew. Chem. 2005, 117, 1899; Angew. Chem. Int. Ed. 2005, 44, 1865-1869; c) A. González, C. López, X. Solans, M. Font-Bardía, E. Molins, J. Organomet. Chem. 2008, 693, 2119-2131; d) P. K. Basu, A. González, C. López, M. Font-Bardía, T. Calvet, J. Organomet. Chem. 2009, 694, 3633-3642; e) S. Pérez, C. López, A. Caubet, R. Bosque, X. Solans, M. Font-Bardía, A. Roig, E. Molins, Organometallics 2004, 23, 224-236.

R. Valters, W. Flitsch, Ring-Chain Tautomerism, Plenum Press, New York, 1985.

a) N. A. Keiko, N. V. Vchisio, L. G. Stepanova, L. I. Larina, Y. A. Chuvashev, E. A. Funtikova, Chem. Heterocycl. Compd. 2008, 44, 1466-1471; b) K. Pilahja, M. Juhasz, H. Kivela, F. Fülöp, Rapid Commun. Mass Spectrom. 2008, 22, 1510-1518; c) M. Juhash, L. Lazar, F. Fülöp, J. Heterocycl. Chem. 2007, 44, 1465-1473.

[9] S. Pérez, C. López, A. Caubet, A. Reig, E. Molins, J. Org. Chem. 2005, 70, 4857-4860.

[10] D. Talancón, R. Bosque, C. López, J. Org. Chem. 2010, 75, 3294-3300.

[11] D. Talancón, C. López, M. Font-Bardía, T. Calvet, J. Quirante, C. Calvis, R. Messeguer, R. Cortés, M. Cascante, L. Baldomà, J. Badia, J. Inorg. Biochem. 2013, 118, 1-12.

[12] For recent advances in these fields, see, for example: a) M. Weiss, W. Frey, R. Peters, Organometallics 2012, 31, 6365-6372; b) K. Chen, S. A. Pullarkat, M. Ma, Y. Li, P.-K. Leung, Dalton Trans. 2012, 41, 5391-5400; c) L. Yang, P. Guan, P. He, Q. Chen, C. Cao, P. Changsheng, S. Yu, Z. Shi, G. Pang, Y. Shi, Dalton Trans. 2012, 41, 5020-5025; d) J. F. Buergler, K. Niedermann, A. Togni, Chem. Eur. J. 2012, 18, 632-640; e) I. Guerrero Rios, A. Rosas-Hernandez, E. Martin, Molecules 2011, 16, 970-1010; f) R. A. Fernandes, J. L. Nallasivam, Org. Biomol. Chem. 2012, 10, 7789-7800; g) A. De Crisci, K. Chung, A. G. Oliver, D. Solis-Ibarra, R. M. Waymouth, Organometallics 2013, 32, 2257-2266; h) K. Hyodo, M. Kondo, Y. Funahashi, S. Nakamura, Chem. Eur. J. 2013, 19, 4128-4134; i) S. Sabater, J. A. 
Mata, E. Peris, Organometallics 2013, 32, 1112-1120; j) H. Nomura, C. J. Richards, Chem. Asian J. 2010, 5, 1726-1740; k) N. Dendele, F. Bisaro, A.-C. Gaumont, S. Perrio, C. J. Richards, Chem. Commun. 2012, 48, 1991-1992.

[13] a) C. López, A. Caubet, S. Pérez, X. Solans, M. Font-Bardía, Chem. Commun. 2004, 540-541;

[14] The molar ratio of the three isomers $6 \mathrm{bI} / 6 \mathrm{bII} / 6 \mathrm{bIII}$ was 1.0:0.86:0.39 for $\mathrm{t}=24 \mathrm{~h}$ and 1.0:0.92:0.38 for $\mathrm{t}=72 \mathrm{~h}$.

[15] Crystal data for 6bIII CH2Cl2: $\mathrm{C} 40 \mathrm{H} 40 \mathrm{Cl} 2 \mathrm{Fe} 2 \mathrm{~N} 2 \mathrm{O} 2 \mathrm{Pd} 2 \cdot \mathrm{CH} 2 \mathrm{Cl} 2, \mathrm{M}=1061.07, \mathrm{~T}=100(2) \mathrm{K}$, orthorhombic, space group $=\mathrm{P} 212121, \mathrm{a}=12.089(2), \mathrm{b}=15.804(2), \mathrm{c}=20.454(3) \AA, \alpha=\beta=\gamma$ $=90^{\circ}, \mathrm{V}=3907.8(19) \AA 3$, Dcalcd. $=1.80 \mathrm{Mgm}-3, \mu=2.441 \mathrm{~mm}-1, \mathrm{~F}(000)=2120$, no. of reflections $=36791$, no. of parameters $=480$; final $\mathrm{R}$ indices $[\mathrm{I}] 2 \sigma(\mathrm{I})]: \mathrm{R} 1=0.0638, \mathrm{wR} 2=$ 0.1640; $\mathrm{R}$ indices (all data): $\mathrm{R} 1=0.0736, \mathrm{wR} 2=0.1692$.

[16] a) A. Bondi, J. Phys. Chem. 1966, 70, 3006-3007; b) A. I. Kitaigorodskii, Molecular Crystals and Molecules, Academic Press, London, 1973.

[17] a) C. López, J. Sales, X. Solans, R. Zquiak, J. Chem. Soc., Dalton Trans. 1992, 2321-2328: b) R. Bosque, C. López, J. Sales, X. Solans, M. Font-Bardía, J. Chem. Soc., Dalton Trans. 1994, $735-745$.

[18] a) E. T. J. Strong, S. A. Cardile, A. L. Brazeau, M. C. Jennings, R. McDonald, N. D. Jones, Inorg. Chem. 2008, 47, 10575-10586; b) A. Albinati, F. Lianza, H. Berger, C. Arz, P. S. Pregosin, Inorg. Chim. Acta 1992, 198-200, 771-780.

[19] J. Vicente, J. A. Abad, A. D. Frankland, M. C. Ramírez de Arellano, Chem. Eur. J. 1999, 5, $3066-3075$.

[20] Crystal data for 7bII: C38H35ClFeNOPPd, $\mathrm{M}=750.34, \mathrm{~T}=293(2) \mathrm{K}$, monoclinic, space group: $\mathrm{P} 21, \mathrm{a}=7.668(7), \mathrm{b}=10.523(6), \mathrm{c}=20.377(13) \AA, \alpha=\beta=90.0, \gamma=94.48(4)^{\circ}, \mathrm{V}=1639(2) \AA 3$, Dcalcd. $=1.520 \mathrm{Mgm}-3, \mu=1.152 \mathrm{~mm}-1, \mathrm{~F}(000)=764$, number of reflections: 17447 , number of parameters: 399 ; final $\mathrm{R}$ indices [II $2 \sigma(\mathrm{I})]$ : R1 $=0.0685$, wR2 $=0.1644$; R indices (all data): $\mathrm{R} 1=0.1122, \mathrm{wR} 2=0.1865$. 

W. Rossiter, H. Hamilton), Wiley, New York, 1986, vol. 4, chapter 4. 
Scheme 1. Ring-chain tautomerism between imines and the 1,3-(N,O) heterocycles formed by a 5- or 6403 endo-trig process.

404

Scheme 2. Synthesis of tetra- and dimetallic cyclopalladated complexes $6 \mathrm{bI}-6 \mathrm{bIII}$ and $7 \mathrm{bI}-7 \mathrm{bIII}$, respectively. Reagents and conditions: i) tautomeric equilibrium between imine 1 and the closed forms 2; this process is solvent-dependent;[10] ii) $\mathrm{Na} 2[\mathrm{PdCl} 4], \mathrm{Na}(\mathrm{OAc}) \cdot 3 \mathrm{H} 2 \mathrm{O}, \mathrm{MeOH}, 298 \mathrm{~K}, 40 \mathrm{~h}$; $\mathrm{SiO} 2$ column chromatography; iii) $\mathrm{PPh} 3$ molar ratio $\mathrm{PdII} / \mathrm{PPh} 3=0.5$ in $\mathrm{CH} 2 \mathrm{Cl} 2$ at $298 \mathrm{~K}$.

Figure 1 Diastereomerically pure platinum(II) complexes recently reported in which imine 1 adopts different modes of binding (L represents dmso).[11]

Figure 2. ORTEP plot of $[\mathrm{Pd}\{\kappa 2-\mathrm{C}, \mathrm{N}\{(\mathrm{C} 6 \mathrm{H} 4)-\mathrm{CH}(\mathrm{OH})-\mathrm{CH}(\mathrm{Me})-\mathrm{N}=\mathrm{CH}-(\eta 5-\mathrm{C} 5 \mathrm{H} 4)\} \mathrm{Fe}(\eta 5-\mathrm{C} 5 \mathrm{H} 4)\}(\mu-$ Pd1-C15 1.990(9), Pd1-N1 2.014(8), Pd1-Cl1 2.353(2), Pd1-Cl2 2.469(2), Pd2-Cl15B 2.020(7), Pd2-

Figure 3 Simplified view of the $\mathrm{C}-\mathrm{H} \cdots \mathrm{Cl}$ contacts between molecules of $[\mathrm{Pd}\{\kappa 2-\mathrm{C}, \mathrm{N}\{(\mathrm{C} 6 \mathrm{H} 4)-$

$\mathrm{CH}(\mathrm{OH})-\mathrm{CH}(\mathrm{Me})-\mathrm{N}=\mathrm{CH}-(\eta 5-\mathrm{C} 5 \mathrm{H} 4)\} \mathrm{Fe}(\eta 5-\mathrm{C} 5 \mathrm{H} 4)\}(\mu-\mathrm{Cl})] 2$ (6bIII) and $\mathrm{CH} 2 \mathrm{Cl} 2$ in the crystals of 6bIII $\mathrm{CH} 2 \mathrm{Cl} 2$.

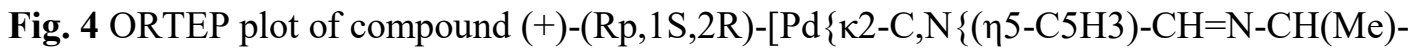

Scheme 3. Synthesis of dimetallic complexes 7aI and 7aII. Reagents and conditions: i) Equimolar amount of PPh3, $\mathrm{CH} 2 \mathrm{Cl} 2,298 \mathrm{~K}$.

Figure 5. Cyclic voltammograms of the platinum(II) complexes with the Schiff base 1 acting as a 
436 Figure 6. Cyclic voltammograms of the (Sp,1S,2R) and (Rp,1S,2R) diastereomers of $[\mathrm{Pt}\{\kappa 2-\mathrm{C}, \mathrm{N}\{(\eta 5-$ $437 \mathrm{C} 5 \mathrm{H} 3)-\mathrm{CH}=\mathrm{N}-\mathrm{CH}(\mathrm{Me})-\mathrm{CH}(\mathrm{OH})(\mathrm{C} 6 \mathrm{H} 5)\} \mathrm{Fe}(\eta 5-\mathrm{C} 5 \mathrm{H} 5)\} \mathrm{Cl}(\mathrm{L})]$ with $\mathrm{L}=$ dmso (5aI, 5aII) or PPh3 (7aI, 438 7aII). Dotted vertical lines correspond to the Epa value of 5aI and 5aII.

439

440 Figure 7. Cyclic voltammograms of the tetrametallic complexes 6bI-6bIII (top) and their corresponding 441 dimetallic derivatives 7bI-7bIII (bottom). The vertical lines correspond to the Epa values of the parent 442 dimeric complexes (6bI-6bIII).

443 
open forms

closed form open form

closed form<smiles>[R]C([R])=NCCO</smiles>

imines

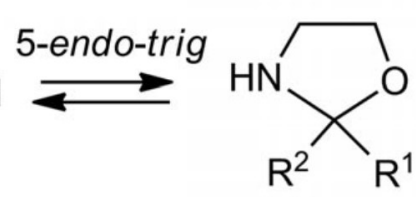

1,3-oxazolidines

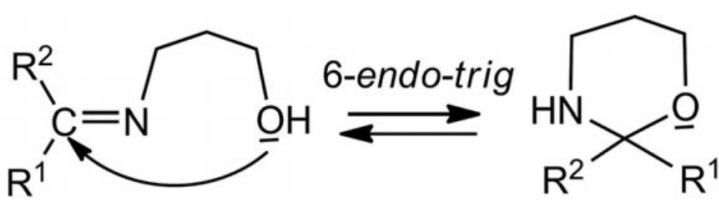

imines

1,3-oxazines 


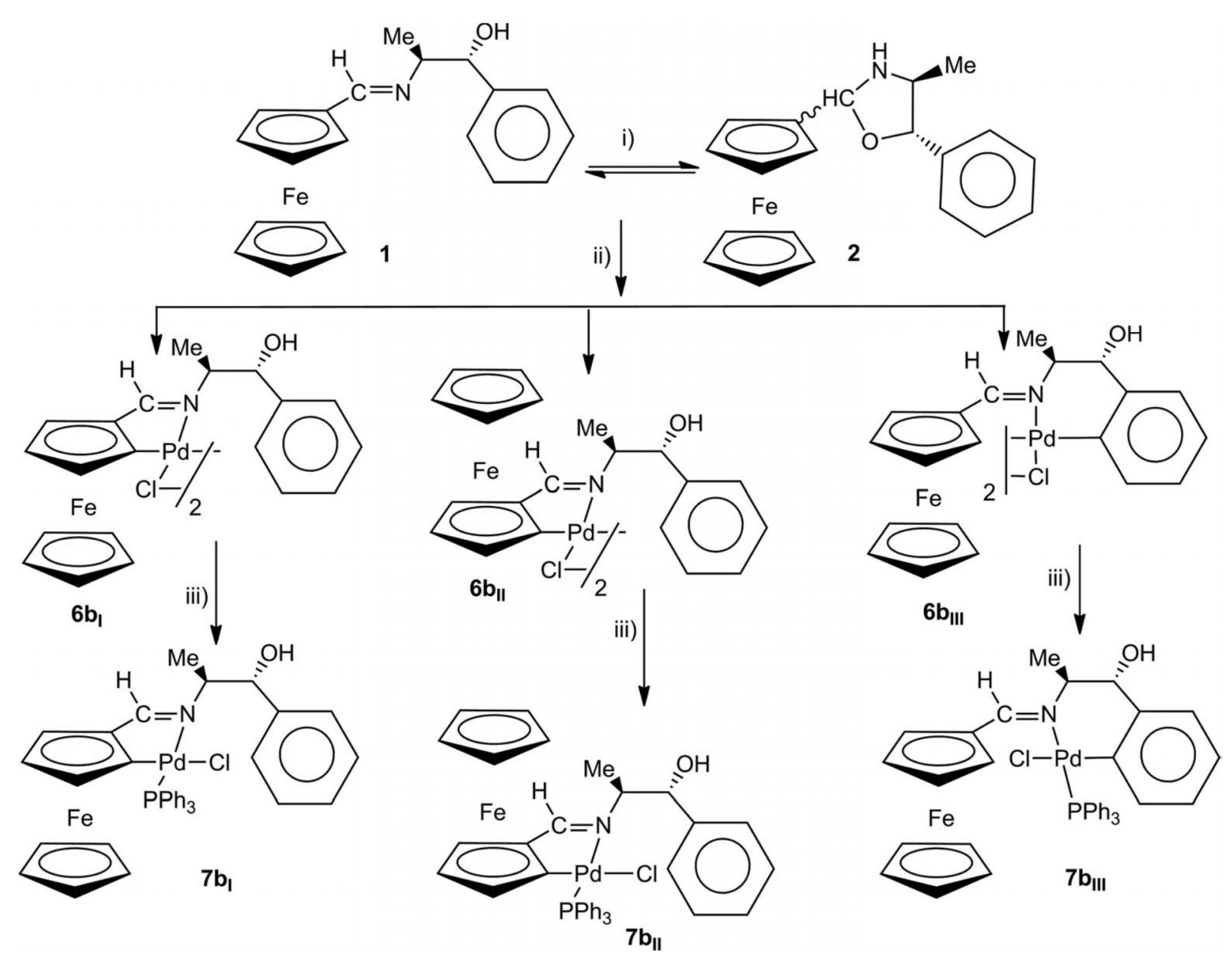


(N) donor<smiles>C[C@H](Cl)[C@H](C)N(/C(=C\c1ccccc1)[C@@H](O)c1ccccc1)[P+](Cl)(Cl)Cl</smiles>

$\mathrm{Fe}$

$\longrightarrow 3 a_{\text {cis- }}$

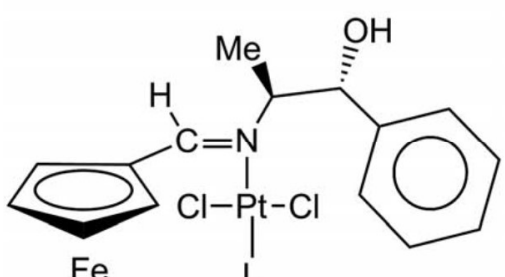

$\mathrm{Fe}$

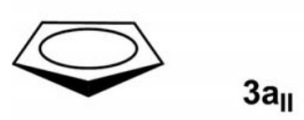

462

463

464

465

466

467

468

469 trans-
FIGURE 1

$(\mathrm{N}, \mathrm{O})^{-}$donor

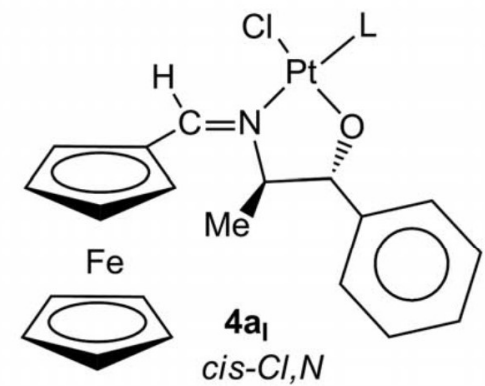

$(\mathrm{C}, \mathrm{N})^{-}$donor
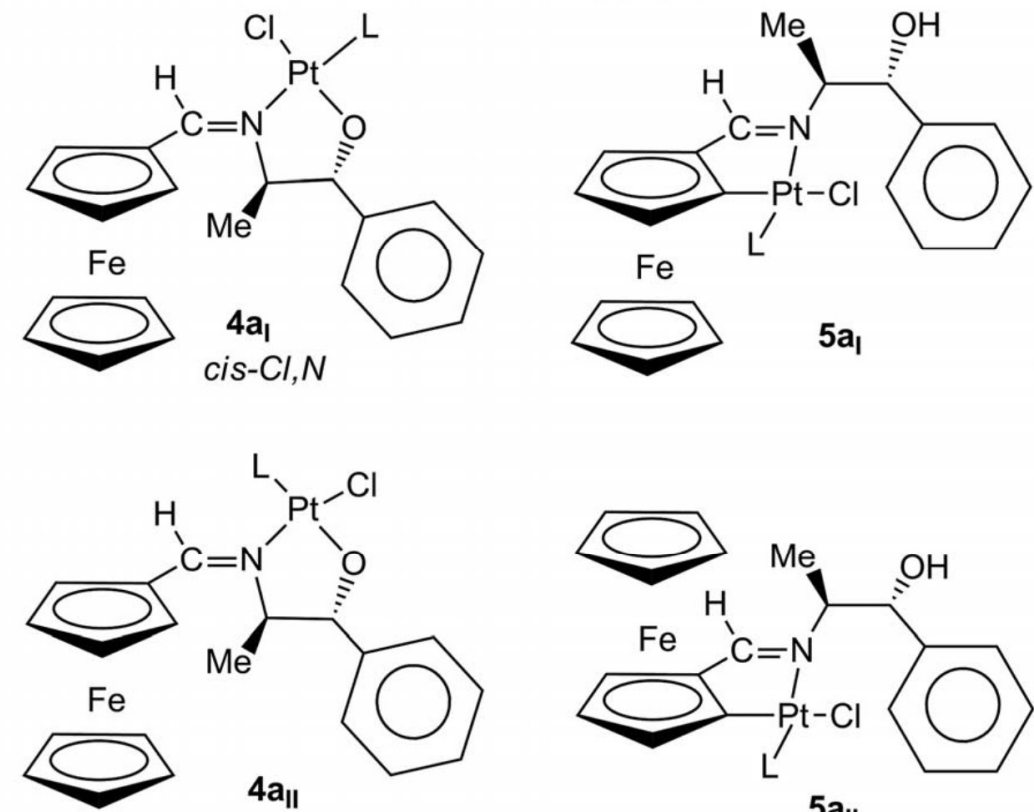

trans-Cl,N

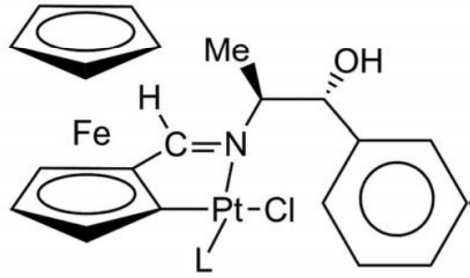

$5 a_{\|}$ 


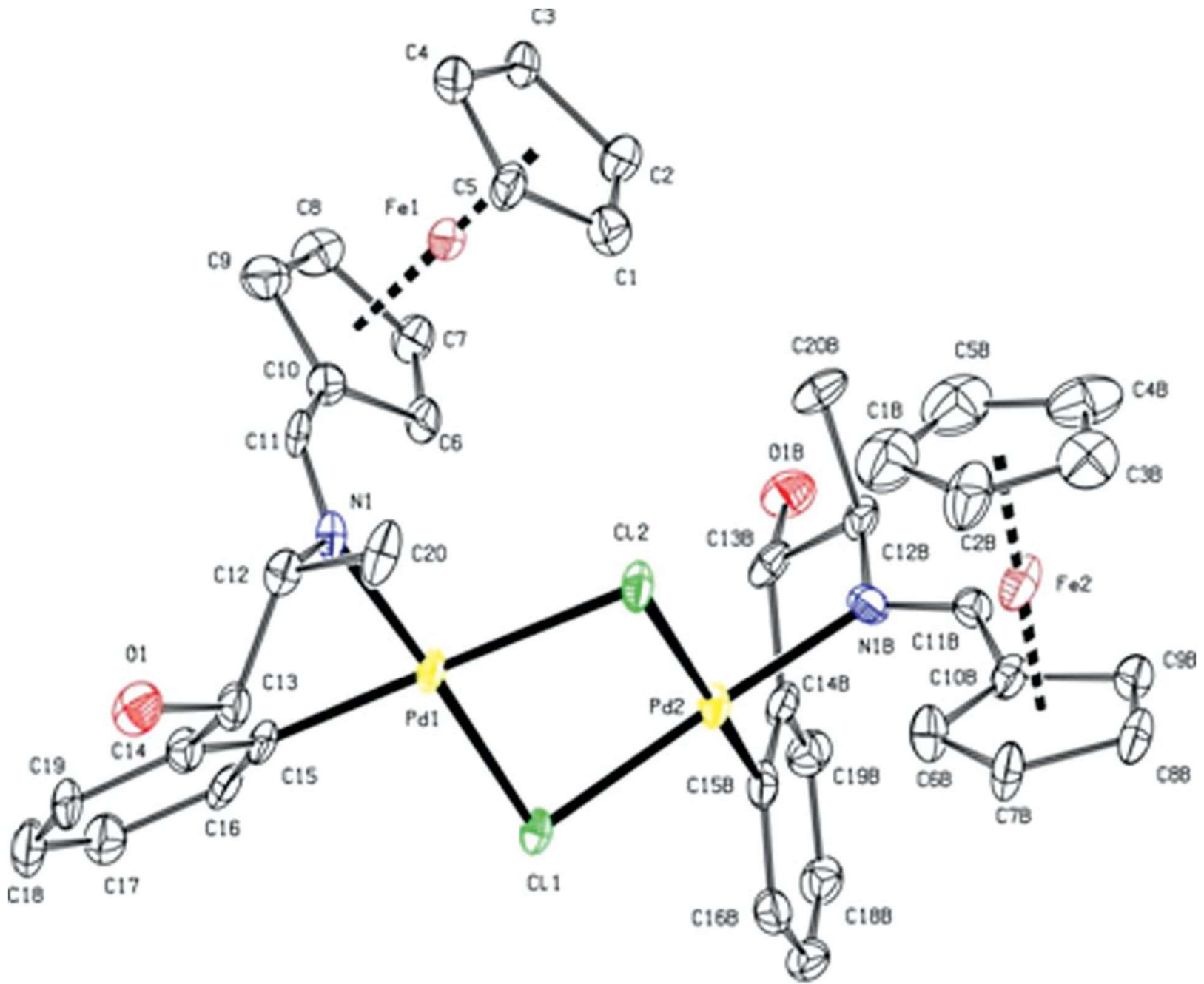


482

483

484

FIGURE 3

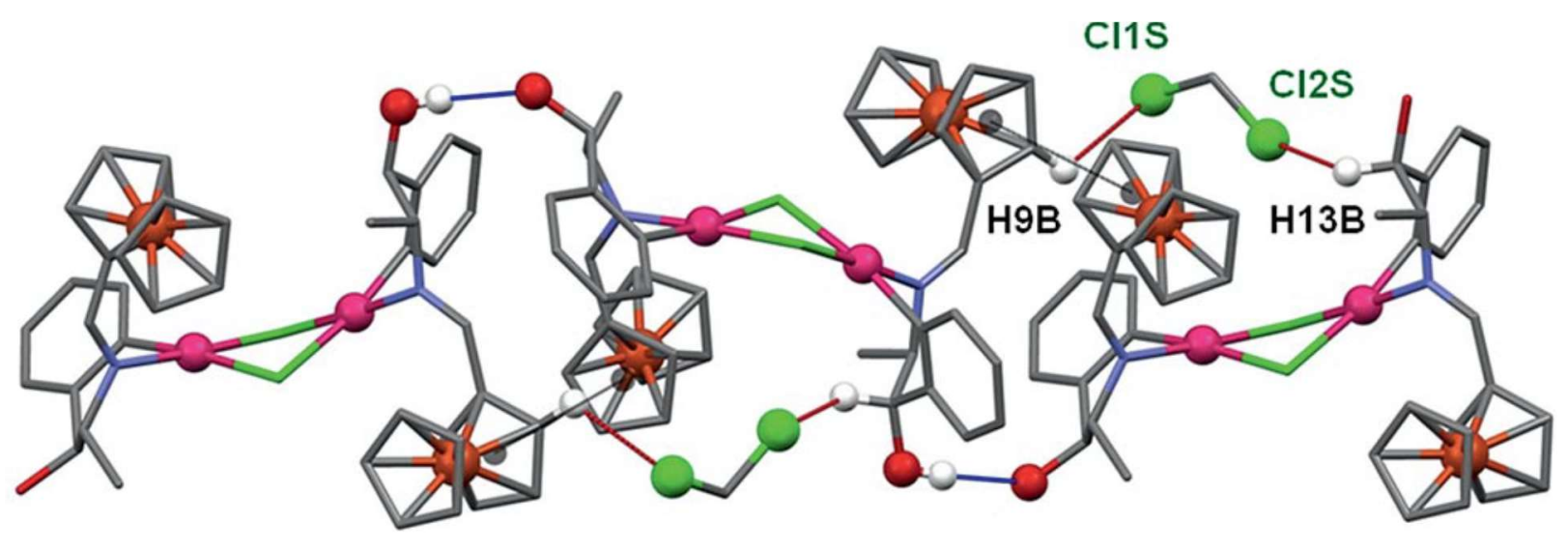

486

487

488 

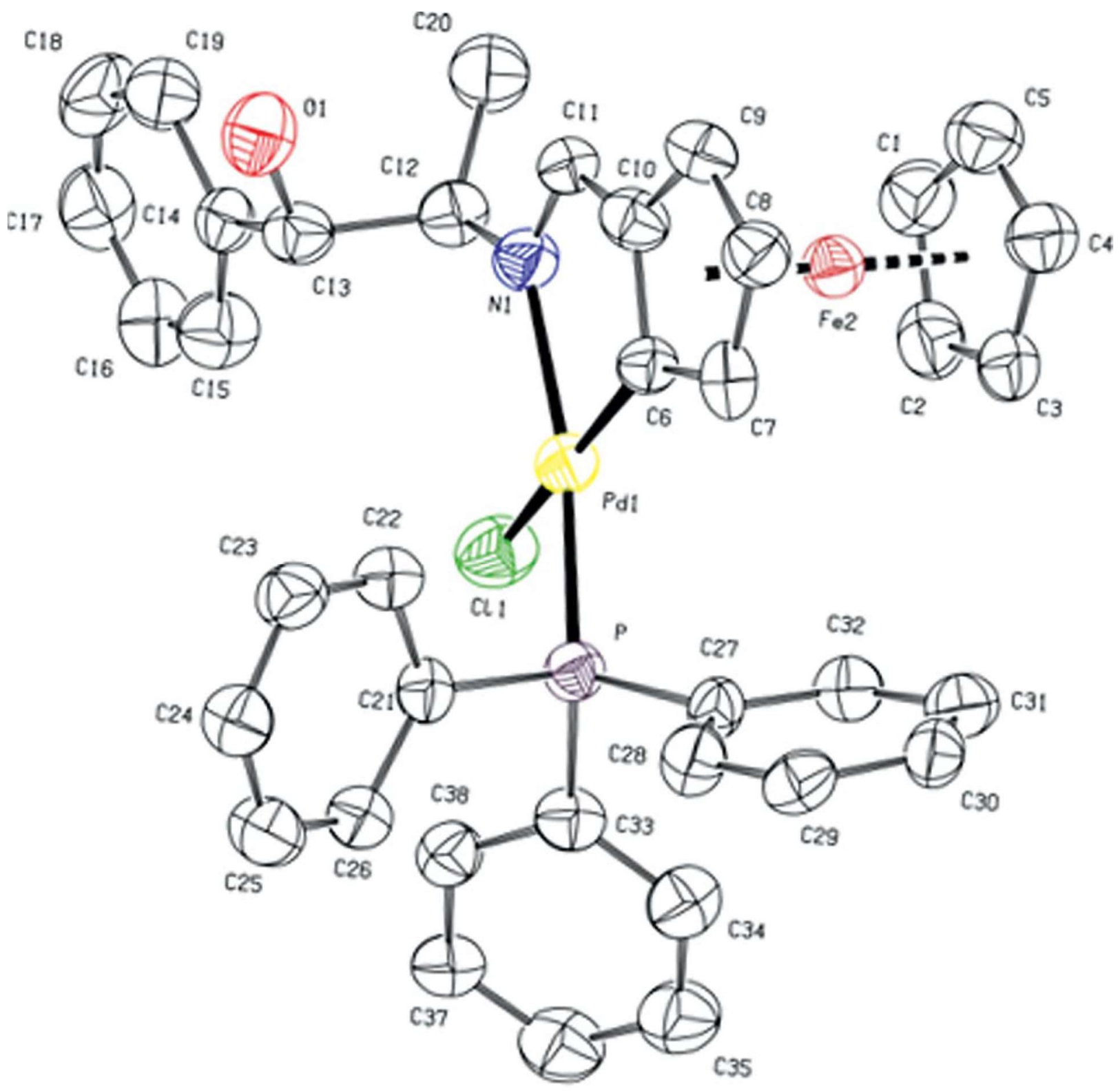

491

C. 36

492

493

494

495 


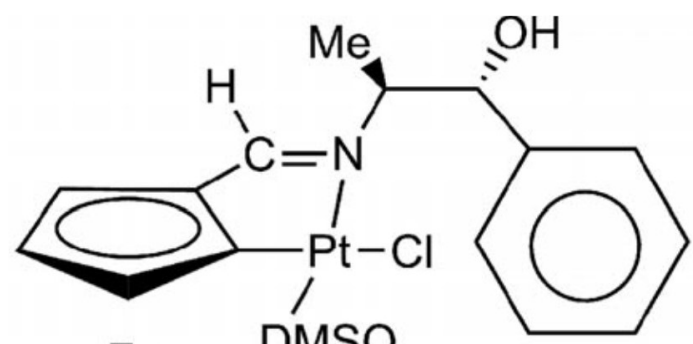

Fe DMSO

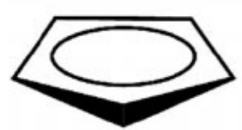

$5 a_{1}$

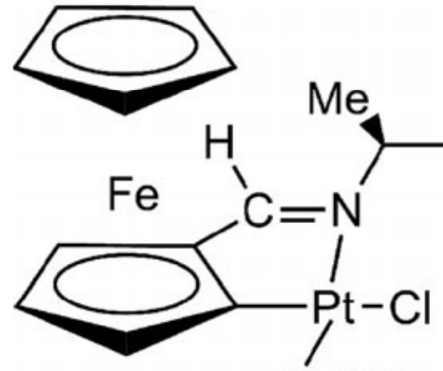

DMSO
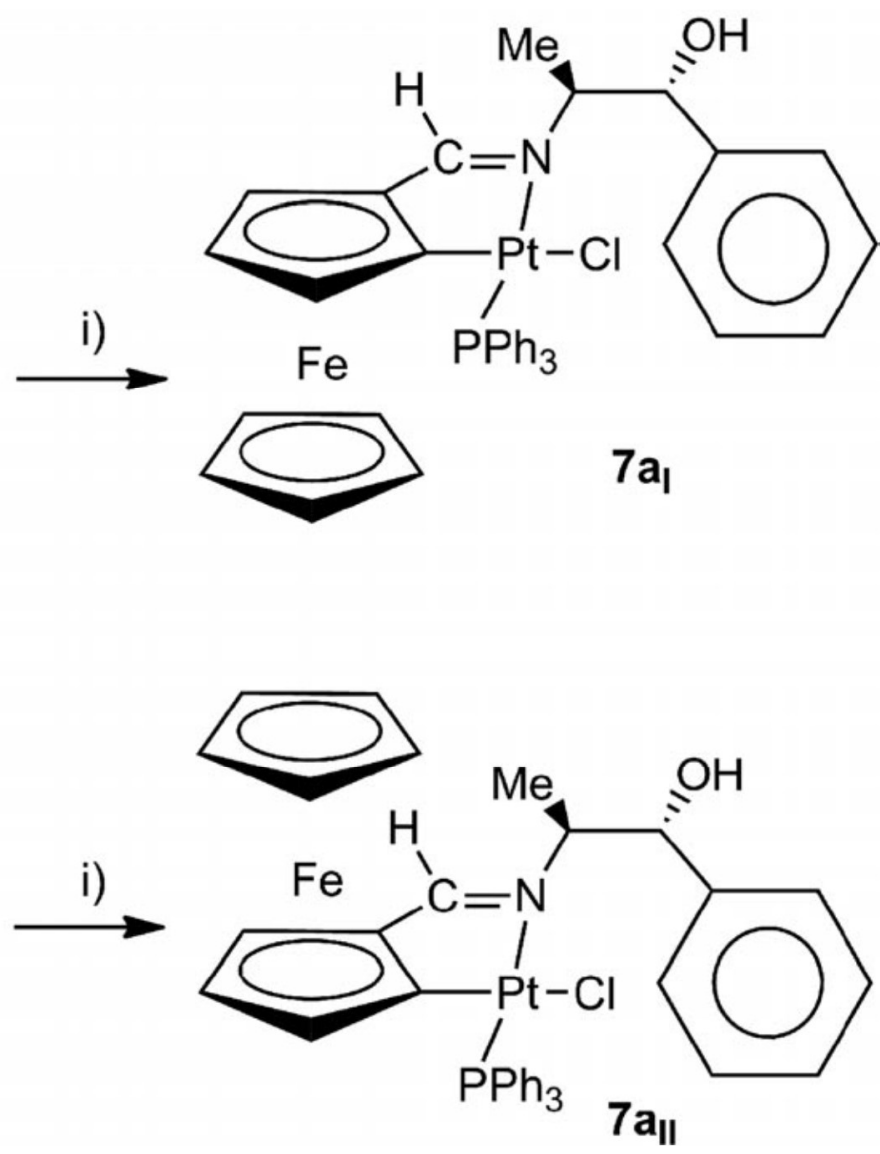
503

504

505

506

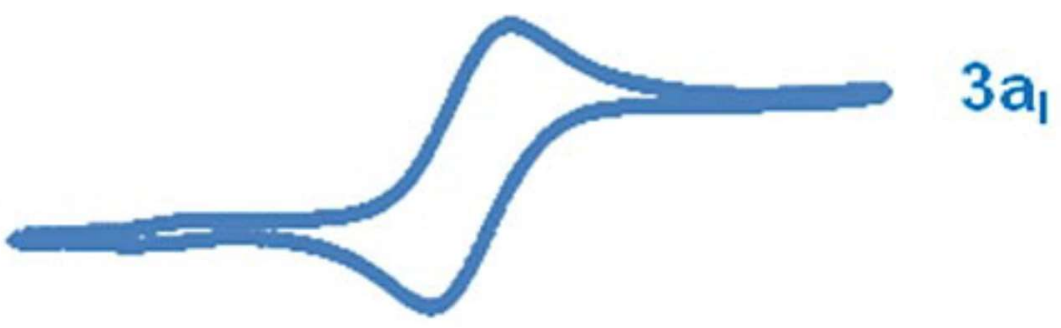

FIGURE 5

506
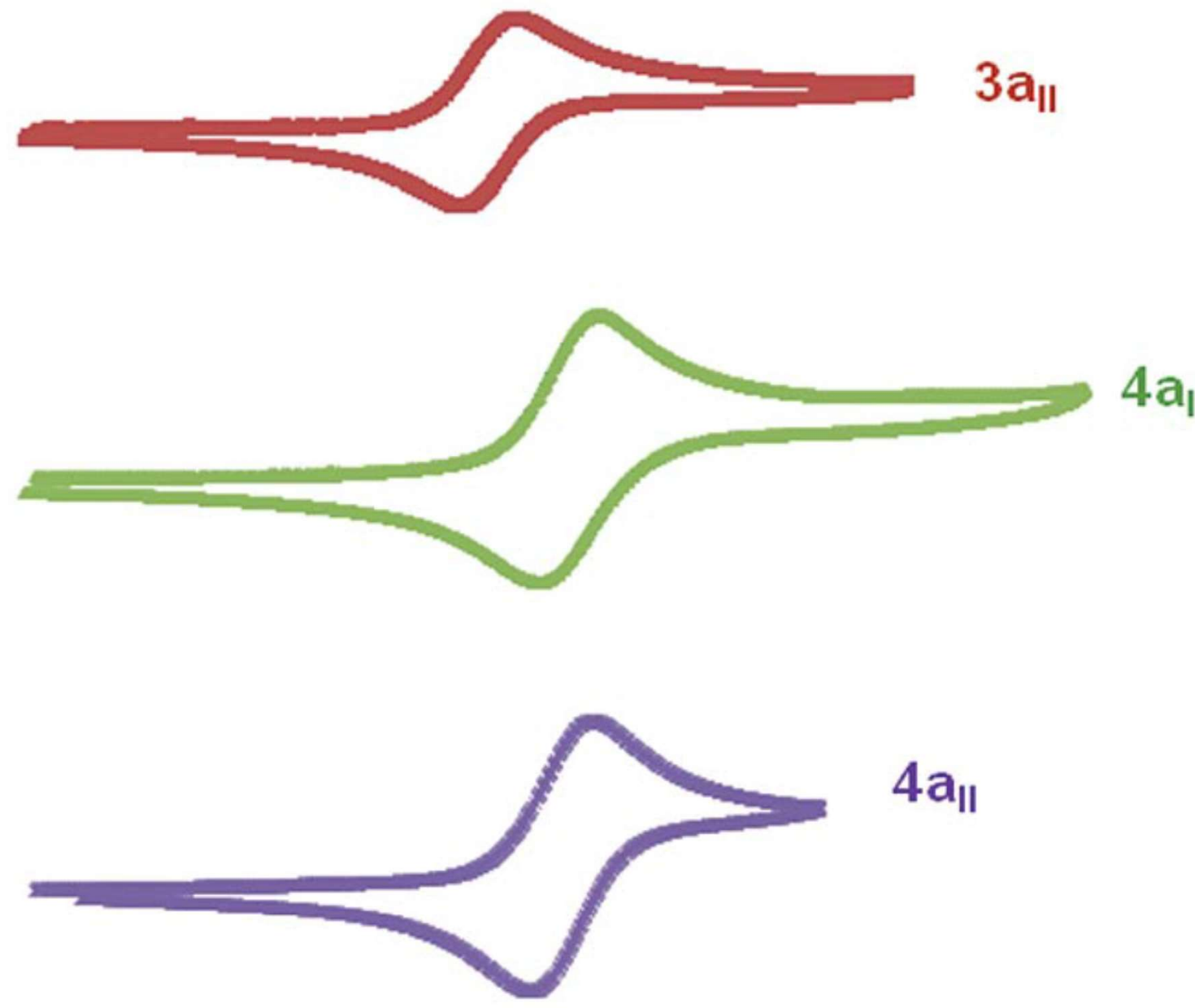

$4 a_{11}$

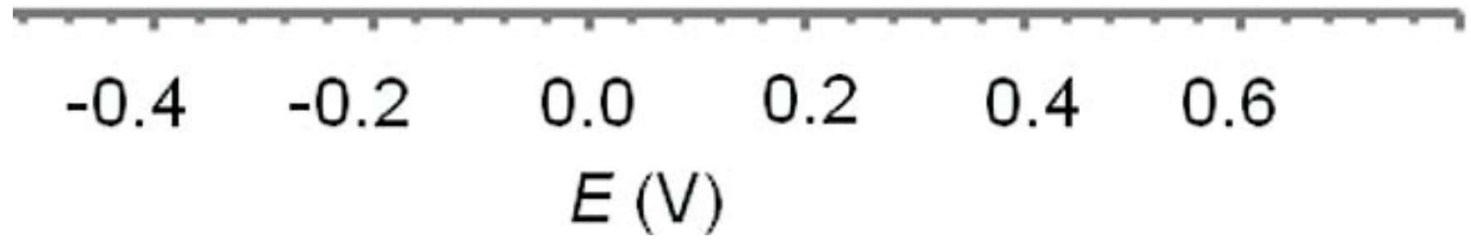

507

508 
FIGURE 6

510

511

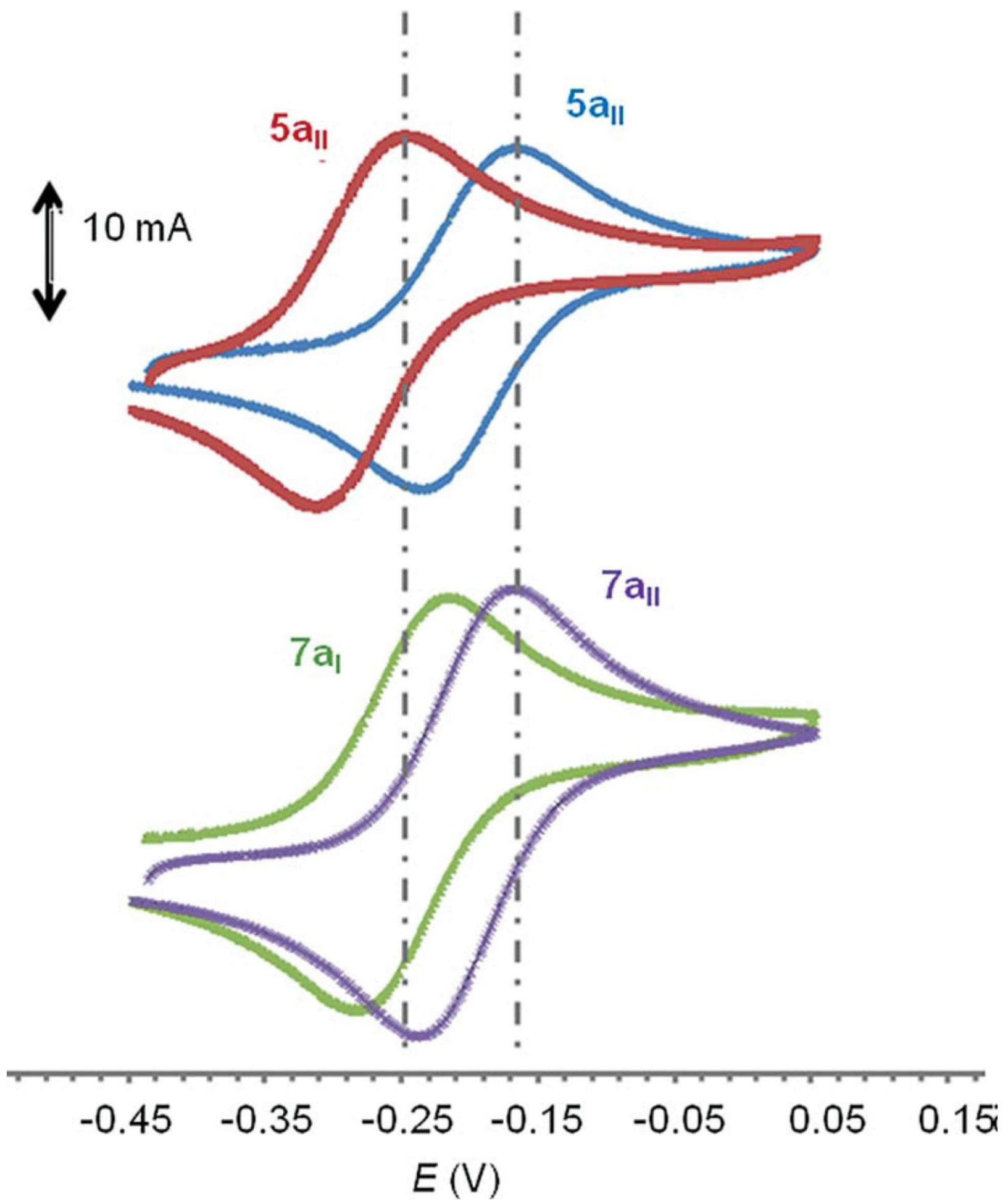



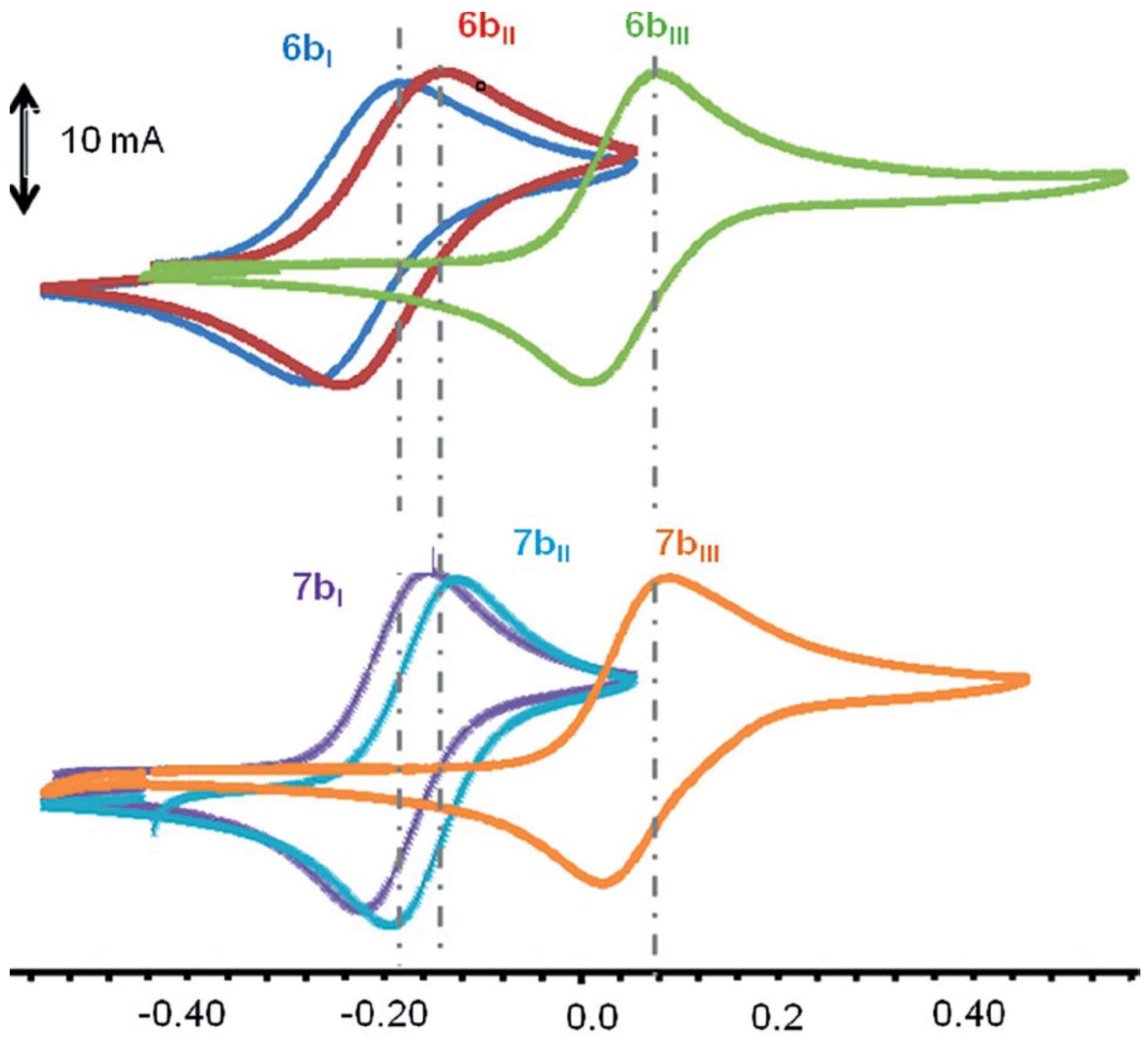

517 
518 Table 1. Summary of the electrochemical data for the complexes studied.[a]

\begin{tabular}{|c|c|c|c|c|c|c|c|c|}
\hline Compound & Binding mode of ligand 1 & & Additional ligands & $E_{\mathrm{pa}}[\mathrm{V}]$ & $E_{\mathrm{pc}}[\mathrm{V}]$ & $\Delta E[\mathrm{~V}]$ & $E_{1 / 2}[\mathrm{~V}]$ & $I_{\mathrm{p}} / I_{\mathrm{pc}}$ \\
\hline $\begin{array}{l}3 a_{1} \\
3 a_{\text {II }} \\
4 a_{1} \\
4 a_{\text {II }} \\
5 a_{1} \\
5 a_{I I} \\
7 a_{1} \\
7 a_{\text {III }} \\
\end{array}$ & $\begin{array}{l}(\mathrm{N}) \\
(\mathrm{N}) \\
(\mathrm{N}, \mathrm{O}) \\
(\mathrm{N}, \mathrm{O})- \\
{\left[\mathrm{C}\left(\mathrm{sp}^{2}, \text { ferrocene), } \mathrm{N}\right]\right.} \\
{\left[\mathrm{C}\left(\mathrm{sp}^{2}, \text { ferrocene), } \mathrm{N}\right]\right.} \\
{\left[\mathrm{C}\left(\mathrm{sp}^{2}, \text { ferrocene), } \mathrm{N}\right]\right.} \\
{\left[\mathrm{C}\left(\mathrm{sp}^{2}, \text { ferrocene), } \mathrm{N}\right]\right.}\end{array}$ & $\begin{array}{l}\text { trans- }(\mathrm{Cl}, \mathrm{Cl}) \\
c \text { ss- }(\mathrm{Cl}, \mathrm{Cl}) \\
\text { trans- }(\mathrm{Cl}, \mathrm{N}) \\
c \text { cls- }(\mathrm{Cl}, \mathrm{N}) \\
\left(\mathrm{R}_{\mathrm{p}}\right) \\
\left(\mathrm{S}_{\mathrm{p}}\right) \\
\left(\mathrm{R}_{\mathrm{p}}\right) \\
\left(\mathrm{S}_{\mathrm{p}}\right) \\
\end{array}$ & $\begin{array}{l}\mathrm{X}=\mathrm{C}, \mathrm{L}=\text { dmso } \\
\mathrm{X}=\mathrm{C}, \mathrm{L}=\mathrm{dmso} \\
\mathrm{X}=\mathrm{C}, \mathrm{L}=\mathrm{dmso} \\
\mathrm{X}=\mathrm{C}, \mathrm{L}=\mathrm{dmso} \\
\mathrm{X}=\mathrm{C}, \mathrm{L}=\text { dmso } \\
\mathrm{X}=\mathrm{C}, \mathrm{L}=\text { dmso } \\
\mathrm{X}=\mathrm{C}, \mathrm{L}=\mathrm{PPh}_{3} \\
\mathrm{X}=\mathrm{C}, \mathrm{L}=\mathrm{PPh}_{3}\end{array}$ & $\begin{array}{l}0.108 \\
0.007 \\
0.197 \\
0.208 \\
-0.250 \\
-0.169 \\
-0.224 \\
-0.136 \\
\end{array}$ & $\begin{array}{l}0.042 \\
-0.084 \\
0.125 \\
0.135 \\
-0.310 \\
-0.237 \\
-0.280 \\
-0.180 \\
\end{array}$ & $\begin{array}{l}0.066 \\
0.091 \\
0.072 \\
0.073 \\
0.067 \\
0.070 \\
0.070 \\
0.063 \\
\end{array}$ & $\begin{array}{c}0.075 \\
-0.028 \\
0.160 \\
0.171 \\
-0.249 \\
-0.203 \\
-0.201 \\
-0.314 \\
\end{array}$ & $\begin{array}{l}1.012 \\
1.009 \\
0.958 \\
1.000 \\
0.900 \\
1.020 \\
0.941 \\
0.938\end{array}$ \\
\hline \multicolumn{9}{|c|}{ Palladium(II) complexes } \\
\hline $\begin{array}{l}6 \mathrm{~b}_{1} \\
6 \mathrm{~b}_{\mathrm{nI}} \\
6 \mathrm{~b}_{\mathrm{mI}} \\
7 \mathrm{~b}_{1} \\
7 \mathrm{~b}_{\mathrm{n}} \\
7 \mathrm{~b}_{\mathrm{mI}}\end{array}$ & $\begin{array}{l}{\left[\mathrm{C}\left(\mathrm{sp}^{2}, \text { ferrocene }\right), \mathrm{N}\right]} \\
{\left[\mathrm{C}\left(\mathrm{sp}^{2}, \text { ferrocene }\right), \mathrm{N}\right]} \\
{\left[\mathrm{C}\left(\mathrm{sp}^{2}, \text { phenyl), N] }\right.\right.} \\
{\left[\mathrm{C}\left(\mathrm{sp}^{2}, \text { ferrocene }\right), \mathrm{N}\right]} \\
{\left[\mathrm{C}\left(\mathrm{sp}^{2}, \text { ferrocene }\right), \mathrm{N}\right]} \\
{\left[\mathrm{C}\left(\mathrm{sp}^{2}, \text { phenyl), N] }\right.\right.}\end{array}$ & $\begin{array}{l}\left(\mathrm{R}_{\mathrm{p}}\right) \\
\left(\mathrm{R}_{\mathrm{p}}\right) \\
- \\
\left(\mathrm{R}_{\mathrm{p}}\right) \\
\left(\mathrm{S}_{\mathrm{p}}\right) \\
-\end{array}$ & $\begin{array}{l}(\mu-\mathrm{Cl})_{2} \\
(\mu-\mathrm{Cl})_{2} \\
(\mu-\mathrm{Cl})_{2} \\
\mathrm{X}=\mathrm{Cl}, \mathrm{L}=\mathrm{PPh}_{3} \\
\mathrm{X}=\mathrm{C}, \mathrm{L}=\mathrm{PPh}_{3} \\
\mathrm{X}=\mathrm{C}, \mathrm{L}=\mathrm{PPh}_{3}\end{array}$ & $\begin{array}{c}-0.171 \\
-0.143 \\
0.074 \\
-0.156 \\
-0.128 \\
0.088\end{array}$ & $\begin{array}{l}-0.263 \\
-0.242 \\
0.008 \\
-0.222 \\
-0.193 \\
-0.021\end{array}$ & $\begin{array}{l}0.097 \\
0.099 \\
0.066 \\
0.056 \\
0.067 \\
0.066\end{array}$ & $\begin{array}{l}-0.217 \\
-0.192 \\
-0.049 \\
-0.189 \\
-0.283 \\
0.055\end{array}$ & $\begin{array}{l}0.874 \\
0.892 \\
1.000 \\
0.909 \\
0.909 \\
1.056\end{array}$ \\
\hline
\end{tabular}

[a] Anodic $\left(E_{\mathrm{pa}}\right)$ and cathodic $\left(E_{\mathrm{pe}}\right)$ potentials, the separation between peaks $\left(\Delta E=E_{\mathrm{pa}}-E_{\mathrm{pc}}\right)$ and half-wave potentials ( $\left.E_{1 / 2}\right)$ and the ratio between the intensities of the anodic and cathodic peaks $\left(I_{\mathrm{r}} / I_{\mathrm{p}}\right)$ for the four pairs of $\mathrm{Pt}^{\mathrm{t}}$ complexes ( $3 \mathrm{a}_{1}$ and $3 \mathrm{a}_{\mathrm{I}}, 4 \mathrm{a}_{1}$ and $4 \mathrm{a}_{1 \mathrm{~b}}$, $5 \mathrm{a}_{\mathrm{I}}$ and $5 \mathrm{a}_{1} .7 \mathrm{a}_{1}$ and $\left.7 \mathrm{a}_{\mathrm{w}}\right)$, in which ligand 1 exhibits different modes of binding [(N),(N,O)] or [C(sp',ferrocene), N], and the tetra- $\left(6 \mathrm{~b}_{\mathrm{m}}\right.$ $6 \mathrm{~b}_{\mathrm{mI}}$ ) and dimetallic $\left(7 \mathrm{~b}_{1}-7 \mathrm{~b}_{\mathrm{mI}}\right)$ palladium(II) compounds prepared in this work (Scheme 1). Data were obtained at a scan rate $v$ of $100 \mathrm{mVs}^{-1}$ and referenoed to the ferrocene/ferricinium couple. 
